\title{
Centro Tradicional de Negocios de Toluca, 2000-2010: ¿oportunidad o decadencia?
}

\section{Traditional Business Center of the city of Toluca, 2000-2010: opportunity or decadence?}

Luis Giovanni Ramírez SÁnchez

\begin{abstract}
This paper consists of the analysis of the vitality or decline of the Traditional Business Center of Toluca (CTN), based on key variables: population, employment, and marginalization. The objective of this text is to examine if the CTN remains a vibrant and attractive place for urban activities or if, on the contrary, it is on a declining path. Unfortunately, the results show that more than 65\% of the Basic Geostatistical Areas (AGEB) of the CTN register some degree of decline. The action or inaction of government agencies and organized society can contribute to the rescue of the CTN or accelerate its decline.
\end{abstract}

Keywords: traditional business center, decadence, population, employment, marginalization.

\section{Resumen}

Este trabajo consiste en el análisis de la vitalidad o decadencia del Centro Tradicional de Negocios de Toluca (CTN) a partir de variables clave: población, empleo y marginación. El objetivo de este texto es examinar si el CTN se mantiene como un lugar vibrante y atractivo para las actividades urbanas o si, por el contrario, está en una trayectoria de decadencia. Lamentablemente, los resultados muestran que más de 65\% de las Áreas Geoestadísticas Básicas (AGEB) del CTN registran algún grado de decadencia. La acción o inacción de las instancias gubernamentales y de la sociedad organizada pueden contribuir al rescate del CTN o acelerar su decadencia.

Palabras clave: centro tradicional de negocios, decadencia, población, empleo, marginación. 


\section{Introducción}

Durante los años sesenta se realizaron violentas manifestaciones urbanas en distintos países del mundo occidental con las que se evidenció que una gran cantidad de ciudades de países desarrollados presentaban serios problemas sociales, económicos y físicos en sus áreas centrales (Inner cities); Estados Unidos e Inglaterra fueron los que más sufrieron este tipo de problemas (Díaz, 2011). El término ciudades centrales se usa en Estados Unidos para referirse a la ciudad original y más antigua de las metrópolis; para el caso mexicano (y latinoamericano, quizá) equivaldría al área tradicionalmente vinculada al Centro Tradicional de Negocios (CTN) (Garrocho y Campos, 2007), a la parte fundacional de la ciudad (Carrión, 2010).

En las ciudades mexicanas y latinoamericanas, el CTN tiene un papel estratégico en la vida social y económica de las áreas urbanas, tanto por sus características simbólicas (e.g. históricas) como funcionales (e.g. principal nodo de transporte público y de comercio peatonal) (Carrión, 2010). Por tanto, la ciudad latinoamericana requiere un CTN dinámico, que sea motor potente de crecimiento económico y desarrollo social (Coulomb, 2012; 2018).

La problemática de las ciudades centrales ha sido tema de innumerables e intensos debates político-académicos (Fisher y Wingo, 2017); diversos gobiernos han invertido enormes cantidades de dinero para poner en práctica políticas de regeneración urbana enfocadas a revitalizar las zonas centrales de las ciudades (Jorgenson et al., 2010); por su parte, los académicos se han dado a la tarea de detectar estos procesos de decadencia, identificar sus causas y aportar propuestas de soluciones. Los ejemplos son diversos (Bingham, 2018; Ghose y Huxhold, 2017), incluso en México (Garrocho, 1994; Garrocho y Campos, 2009).

No obstante, a pesar de los esfuerzos que se han realizado por evadir los problemas de las ciudades centrales en diversas partes del mundo, la decadencia persiste y parece que paulatinamente tiende a profundizarse en diversas ciudades del primer mundo (Wagner et al., 2019), de Latinoamérica (Carrión, 2010) y de México (González, 2018; Flores et al., 2013). Este proceso de decadencia se manifiesta de diversas maneras, pero muy claramente en términos de desempleo, deterioro social y pobreza, lo que incrementa las desigualdades sociales y la degradación del medio ambiente (desde Robson, 1988, hasta Turok et al., 2019).

En México, el estudio de los CTN se ha enfocado casi exclusivamente a las grandes ciudades del centro del país: Ciudad de México, Puebla, Querétaro y Toluca, principalmente (Salinas, 2013); la evidencia no es abundante, pero se sabe que sería un error pensar que los problemas que 
registran los CTN de las grandes ciudades mexicanas y latinoamericanas son iguales y tienen las mismas causas que los de las áreas centrales de las ciudades del primer mundo (Pauta, 2019).

Sin embargo, para el caso de México, sí es relevante considerar que nuestros sistemas metropolitanos están inmersos en un contexto altamente globalizado con intensas interacciones macro-regionales con Estados Unidos y Canadá; por esto, la evidencia disponible muestra que diversas ciudades mexicanas sufren problemas en sus CTN que tienen cierta similitud con los de las áreas centrales de algunas de países desarrollados (Simmons et al., 2016; 2018).

Así las cosas, se puede plantear la hipótesis de que los CTN de las grandes metrópolis mexicanas registran un proceso de decadencia, similar en lo general a los que presentan las áreas centrales de ciudades de países desarrollados, pero diferente en sus singularidades.

En este documento se evalúa la situación del CTN de la Zona Metropolitana de Toluca (ZMT); es un trabajo de investigación orientado a la formulación de políticas públicas. Se analizan tres aspectos clave que reporta la literatura especializada: la evolución de las oportunidades de empleo, el proceso de crecimiento demográfico y los cambios en los niveles de marginación social (Shen y Kee, 2017) y que ya han sido considerados para analizar el CTN de ciudades mexicanas (Garrocho, 1994).

\section{Definiciones y elementos teóricos básicos}

\subsection{Ciudad central y Centro Tradicional de Negocios}

Gran parte de la literatura latinoamericana ha considerado como sinónimos los conceptos de ciudad central y CTN. La ciudad central es un concepto norteamericano que se refiere al asentamiento original de las grandes ciudades que luego se expandieron de manera discontinua (v.g. sprawiling), dejando atrás a los más pobres y vulnerables (Leduff, 2014). El concepto de ciudad central supone problemas en su definición teórica y operativa (Toribio, 2004). De acuerdo con Garrocho y Flores (2009), la ciudad central no presenta continuidad en su distribución espacial, sus límites son ambiguos e inciertos y en muchas ocasiones no tiene su localización en el centro de la zona urbana.

En algunos casos, la ciudad central puede estar definida por los cascos históricos e industriales más antiguos y se puede ubicar entre el centro tradicional de la ciudad o los llamados distritos centrales de negocios (CBD: por sus siglas en inglés) y los suburbios (Díaz y Escamilla, 2018). 
Se puede decir que la ciudad central es una zona de transición, de acuerdo con el modelo de anillos concéntricos de Burgess (1925), pero varía en forma, extensión y localización; actualmente, la ciudad central ha cambiado su estructura de monocéntrica a policéntrica (Fuentes y Hernández, 2015; Vecslir, 2019). Esto le ha ocasionado una pérdida de centralidad y una disminución de su importancia ocupacional respecto a otras áreas de la ciudad (Salazar y Sobrino 2010).

Usualmente, la ciudad central se localiza cercana al CBD de la ciudad, está ocupada por grupos de población de bajos ingresos que no pueden pagar renta en otras zonas de la ciudad, hay viviendas deterioradas, con hacinamiento y baja disponibilidad de bienes, servicios y empleo (Gregory et al., 2009; Sobrino, 2007).

El CTN en México y en múltiples ciudades latinoamericanas coincide geográficamente con el centro histórico (Simmons et al., 2018). Como lo dice muy bien Carrión (2010), se trata de un espacio público por excelencia, un elemento articulador de la ciudad y debe ser siempre un Gran Proyecto Urbano. En el siglo XXI, la centralidad histórica de las ciudades latinoamericanas debe mantener su simbolismo, pero debe rediseñarse para cumplir nuevas funciones y ser un potente motor del desarrollo urbano, una plataforma de innovación. "La centralidad histórica debe ser entendida como proyecto y no sólo como memoria" (Carrión, 2010; 2005: 90).

El concepto ciudad central es más funcional que espacial. Se refiere a un efecto del proceso de urbanización, no a una localización (Arteaga, 2005; Garrocho y Campos, 2007; Suárez-Lastra y Delgado-Campos, 2010); implica la presencia de diversos atributos negativos en una o varias zonas del área urbana que, en conjunto, han llegado a conformar la idea de la ciudad central como área problema. En cambio, el CTN en las ciudades mexicanas es un espacio simbólico de vital importancia para toda la ciudad. No se quedó atrás por un proceso de urbanización disperso que discrimina a los más pobres, sino por la competencia de nuevas centralidades urbanas altamente competitivas, enfocadas al sector terciario, apalancadas en clústeres de negocios modernos y planificados que discriminan a los menos eficientes (Simmons et al., 2018).

En estos términos, se puede afirmar que en las ciudades mexicanas no existen las ciudades centrales, como en los países del primer mundo (especialmente en Estados Unidos de América), lo que sí existen son los CTN, que implican mucho más que las ciudades centrales, ya que tienen un profundo valor histórico, social, político, simbólico, económico. No sólo son un lugar estratégico para vivir y trabajar, sino punto vital de la vida colectiva, de la manifestación política, de la plaza en el sentido más amplio del término (Campos, 2011). 
El desafío para los CTN en México y Latinoamérica es mantenerse vibrantes, dinámicos, competitivos como lugares para vivir y trabajar. Que sean lugares que sumen nuevas funciones centrales a sus notables características de "espacio público por excelencia", estratégicos para la vida social urbana (Carrión, 2010: 31); ${ }^{1}$ requerimos CTN vivos, con pasado y con futuro, no congelados en la historia como museos vivientes o como zonas boutiques que excluyen y atentan contra el rol social fundamental del CTN (Carrión, 2010). ${ }^{2}$

Sin embargo, la ciudad central y el CTN comparten numerosas posibilidades de convertirse en zonas problema. ${ }^{3}$ Cuando esto ocurre, dichas zonas se caracterizan por, al menos, tres aspectos fundamentales:

i. Decadencia. Declinan en lo económico, demográfico y social, esto es: disminuyen el empleo, la población y los niveles de vida (Leduff, 2014; Flores et al., 2013).

ii. Degradación. Registran altos grados de contaminación atmosférica, visual, sonora; deterioro de la vivienda, hacinamiento; se concentra la población adulta mayor y la poco calificada, abundan las familias uniparentales y desempleados (Garrocho y Campos, 2015; 2016).

iii. Desesperanza. Es un sentir colectivo de desaliento y pesimismo sobre la resolución de los problemas de la ciudad central (Haase et al., 2003; Haase et al., 2006).

La ciudad central y el CTN, como zonas problema, se pueden abordar desde diversas perspectivas. En términos de agregación, los extremos serían un enfoque exhaustivo que considere la decadencia, degradación y desesperanza, lo que implica el manejo de múltiples variables, hasta uno estratégico, orientado a la planeación, que se concentre en la dimensión de la decadencia y en algunas variables clave. Este trabajo se inserta en este segundo enfoque.

\subsection{Enfoques teóricos sobre la problemática del CTN}

Diversos autores han estudiado la problemática del CTN, han analizado numerosos aspectos y propuesto soluciones para revertir su decadencia. Matthews (1991) distingue seis perspectivas que intentan explicar los

\footnotetext{
${ }^{1}$ Vale aprovechar el momento para recomendar el trabajo de Carrión (2010), quizá el pensador más profundo sobre los centros tradicionales de las ciudades latinoamericanas.

${ }^{2}$ La concepción del CTN boutique a veces incrementa su escala e incluye asentamientos completos (Tommei y Benedetti, 2014).

${ }^{3}$ A pesar de que en apariencia que la población (sobre todo joven) está regresando a vivir a algunos CTN (Hiernaux y González, 2008), este no parece ser el caso del CTN de la ZM de Toluca (Flores et al., 2013).
} 
problemas del CTN (figura 1), las seis tienen tres dimensiones fundamentales: A. La física: de acuerdo con este enfoque, los problemas que aquejan al CTN se solucionan desde la planeación física, por parte de arquitectos, urbanistas e ingenieros, que proponen restaurar ( $\mathrm{y}$ a veces demoler) la ciudad central, crear nuevos accesos, zonificar, regular el uso del suelo y desarrollo de nuevas áreas; B. La social: este enfoque propone mejorar el entorno social como solución a los problemas del CTN, centrándolos en tres aspectos principales: cultura de la pobreza, ciclo de deterioro y fallas institucionales; C. La económica: plantea la idea que de que el CTN enfrenta serias dificultades para generar y sostener, a largo plazo, fuentes de empleos que garanticen un adecuado nivel económico de la población que habita la zona, debido a la inadecuada distribución de los recursos y al conflicto estructural de las sociedades capitalistas.

Figura 1

Diferentes explicaciones de los problemas de los CTN

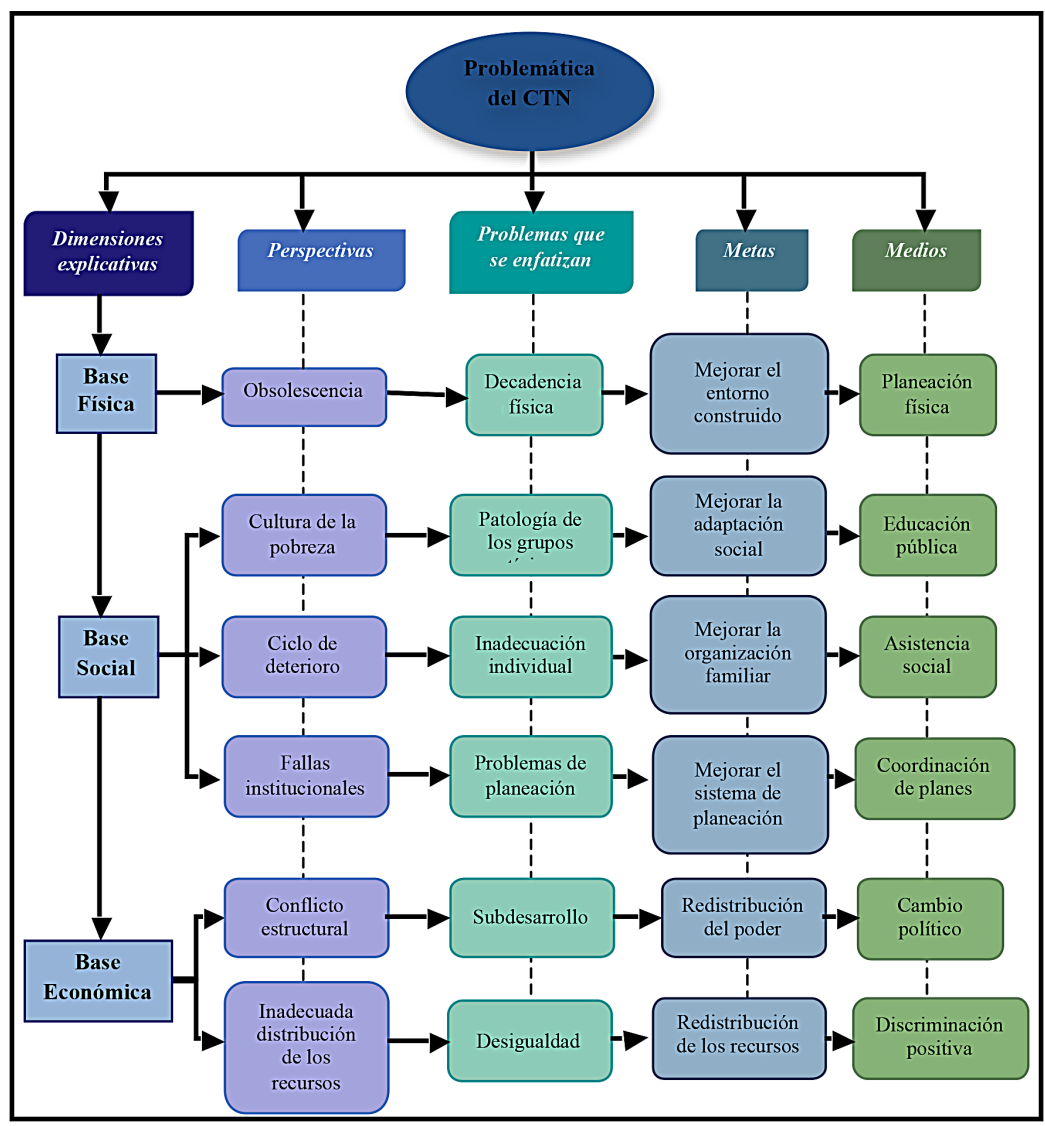

Fuente: elaboración propia a partir de Stewart (1986), Lawless (1996) y Wilson et al. (1998). 
Éstas son algunas explicaciones teóricas de los problemas de los CTN; sin embargo, la diversidad de argumentos para intentar explicar el mismo proceso resulta sospechosa: la riqueza de explicaciones puede denotar pobreza de comprensión; por otro lado, no existe, para el caso mexicano y menos para la ZMT, un bagaje de investigación concreto para contrastar y evaluar las propuestas abstractas de las teorías disponibles. ${ }^{4}$ En este contexto epistemológico y con la evidencia disponible se intenta describir, en lo que sigue del texto, la dinámica del CTN de la Zona Metropolitana de Toluca y examinar si, como parece, se encuentra inmerso en un proceso de decadencia.

\section{Metodología: indicadores y zona de estudio}

El CTN bajo estudio se localiza en la ZMT: la quinta más poblada de México (2.3 millones de habitantes en 2020: Conapo, 2012). ${ }^{5}$ Se ubica en el municipio de Toluca (937,994 habitantes en 2020: Conapo, 2012), que es la sede de la capital del Estado de México y principal municipio de la ZMT.

Aquí se revisará el comportamiento de tres variables clave para examinar el proceso de cambio socioespacial del CTN entre 2000 y 2015 (de acuerdo con la disponibilidad de información oficial): $i$. Oportunidades del empleo, ii. Dinámica poblacional y iii. Niveles de marginación; como mencionamos, estas variables son clave para analizar los CTN (Matthews, 1991; Hall, 2014; Flores et al., 2013).

El nivel de agregación espacial de este trabajo es el de Área Geoestadística Básica Urbana (AGEB). Se analizó a este nivel debido a que no se cuenta con una delimitación territorial más detallada que contenga la información que se requiere para llevar a cabo el estudio. Las fuentes de información usadas fueron los Censos Generales de Población y Vivienda (Inegi: 2011a y 2011b), el índice de marginación se obtuvo de Conapo (2016) y los datos de empleo se recopilaron del Directorio Estadístico Nacional de Unidades Económicas (Inegi, 2018) para los años 2010 y $2015 .^{6}$

${ }^{4}$ A pesar de los notables esfuerzos de Hiernaux y González (2018), Coulomb (2018), Ziccardi (2019), entre otros destacados investigadores, y de los estudios de Garrocho y Flores (2019), Garrocho y Campos (2009) y Ramírez (2020) sobre el CTN de la ZMT.

${ }^{5}$ De acuerdo con la Conapo, la ZMT está conformada por 16 municipios: Almoloya de Juárez con 185,061 habitantes, Calimaya con 59,285, Chapultepec 12,701, Lerma 157,467, Metepec 243,918, Mexicaltzingo 13,563, Ocoyoacac 70,816, Otzolotepec 89,638, Rayón 14,407, San Antonio la Isla 30,878, San Mateo Atenco 80,208, Temoaya 107,918, Tenango del Valle 90,911, Toluca 937,994, Xonacatlán 54,038 y Zinacantepec con 198,889 habitantes.

${ }^{6}$ La razón por la cual se consideraron los datos económicos de 2010 y 2015 fue la disponibilidad de información a la escala en que se trabajó; para sustentar esta decisión se consideró la información de 
Todas estas fuentes permiten el manejo de la información a escala de AGEB, para su manejo se utilizó la amplitud de rango con el fin de generar cuatro categorías en cada una de las variables. Las dimensiones, temáticas generales y los indicadores que manejamos permitieron examinar con detalle suficiente el proceso de cambio del CTN (cuadro 1). Con la finalidad de que el presente trabajo sea replicable (y útil para gobiernos locales), se ha empleado una metodología sencilla, utilizando variables de fácil acceso que brindan una perspectiva del grado de desarrollo de la zona de estudio, en este caso el CTN de la Zona Metropolitana de Toluca.

\section{Cuadro 1}

Indicadores de dinámica del CTN, elaboración y formulación ${ }^{7}$

\begin{tabular}{lll}
\hline Evidencias & \multicolumn{1}{c}{ Indicador } & \multicolumn{1}{c}{ Explicación } \\
\hline Población & $\begin{array}{l}\text { Población } \\
\text { absoluta }\end{array}$ & $\begin{array}{l}\text { Este indicador devela el comportamiento de la pobla- } \\
\text { ción en el periodo de tiempo analizado (2000-2010). } \\
\text { Si hay disminución de la población en términos abso- } \\
\text { lutos se puede considerar como decadencia y viceversa. }\end{array}$ \\
\hline Empleo & Empleo & Son las oportunidades de empleo en el área de estudio. \\
Pobreza & $\begin{array}{l}\text { Índice de } \\
\text { marginación }\end{array}$ & Zonas del CTN según su grado de marginación. \\
\hline
\end{tabular}

Fuente: elaboración propia a partir de Matthews (1991), Hall (2014) y Flores et al. (2013).

\subsection{Delimitación del área de estudio}

En principio, se consideró como CTN de la ZMT el área que delimitaron Garrocho y Flores (2009), quienes definieron los límites del CTN mediante el conteo de flujo de peatones (v.g. flujoscopía peatonal); este método les permitió establecer las fronteras espaciales del centro, clasificar las vialidades según la intensidad de flujos e identificar la localización de los principales ejes de oportunidades de negocio.

Sin embargo, esta delimitación del CTN cortaba parte de las AGEB en las que se organiza la información estadística del CTN. En consecuencia, se decidió tomar como área de estudio la totalidad de la superficie de las AGEB que tocan el CTN, definido por Garrocho y Flores (2009) (figura 2). Así, nuestra delimitación del CTN tiene una superficie de 821 hectáreas, con un total de 17 AGEB (cuadro 2), es 45\% más amplia que la zona definida por Garrocho y Flores (2009), puede ser menos precisa, pero es una delimitación que nos asegura incorporar todo el CTN.

Flores et al. (2013) y Garrocho y Campos (2007 y 2009), donde se vio que la dinámica del empleo en el CTN en el periodo 2000-2010 es similar en las fechas en que realizaron los trabajos estos autores.

${ }^{7} \mathrm{El}$ trabajo se realizó mediante el análisis de los cambios que presentaron las evidencias entre los años 2000 y 2010. 


\section{Figura 2}

\section{Localización del área de estudio}

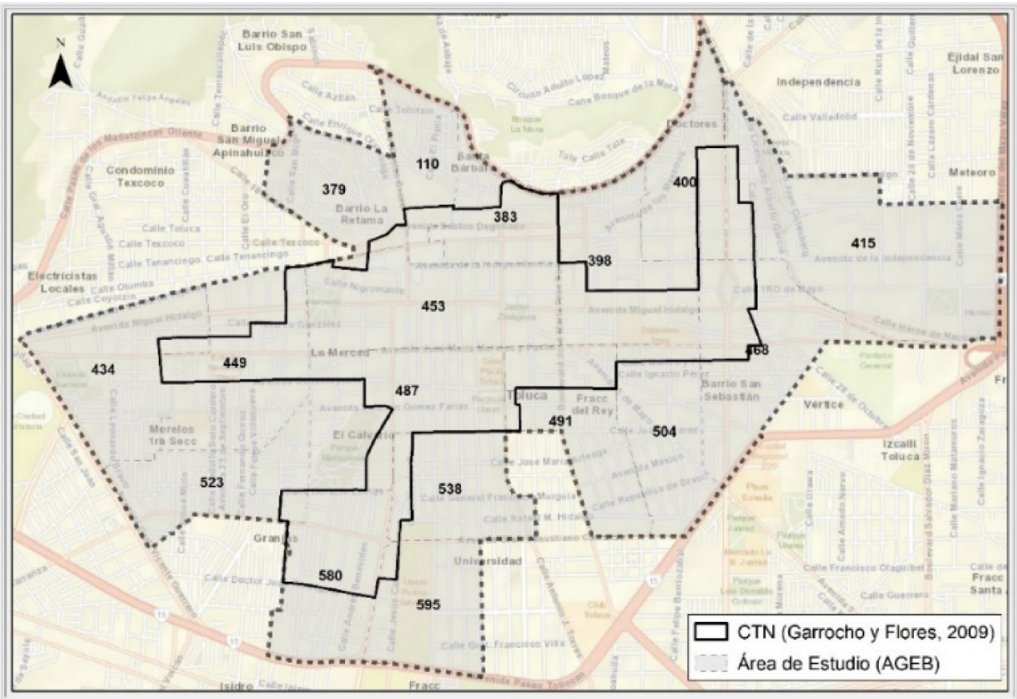

Fuente: elaboración propia a partir de Garrocho y Flores (2009) e Inegi (2018).

\section{Cuadro 2}

Áreas Geoestadísticas Básicas (AGEB) presentes en el CTN

\begin{tabular}{cccc}
\hline$A G E B$ & $\begin{array}{c}\text { Superficie } \\
\text { (ha) }\end{array}$ & AGEB & $\begin{array}{c}\text { Superficie } \\
\text { (ha) }\end{array}$ \\
\hline 538 & 38.25 & 453 & 62.08 \\
434 & 53.05 & 595 & 38.69 \\
110 & 26.86 & 383 & 28.27 \\
379 & 35.31 & 468 & 58.63 \\
398 & 50.98 & 415 & 104.63 \\
400 & 37.07 & 504 & 39.28 \\
487 & 58.47 & 580 & 45.01 \\
523 & 41.47 & 449 & 57.67 \\
491 & 45.28 & & 821 \\
\hline
\end{tabular}

Fuente: elaboración propia a partir de Inegi (2018). 


\section{Población}

\subsection{Evidencia 1: dinámica de la población absoluta del CTN}

En términos absolutos, la población total del CTN disminuyó casi $22 \%$ entre 2000 y 2010 . Había 65,619 habitantes en 2000 y 51,308 en 2010, es decir, el CTN perdió poco más de uno de cada cinco de sus residentes en sólo 10 años. Desde cualquier punto de vista, esto significa un acelerado proceso de despoblamiento. Si revisamos dónde ocurrió el despoblamiento, observamos que es un proceso generalizado en todo el CTN: las 17 AGEB que comprenden el área de estudio redujeron su población. Para examinar en detalle la intensidad espacial del despoblamiento, se calcularon cuatro rangos $^{8}$ porcentuales de pérdida poblacional, lo que permitió clasificar microzonas al interior del CTN según la intensidad del decrecimiento (cuadro 3).

\section{Cuadro 3}

\section{Cambios en la población absoluta en el CTN} por AGEB, 2000-2010

\begin{tabular}{lccccc}
\hline $\begin{array}{c}\text { Rangos } \\
\text { de cambio de } \\
\begin{array}{c}\text { población } \\
\text { (detrimento) }\end{array}\end{array}$ & AGEB* & \multicolumn{2}{c}{ Población absoluta } & \multicolumn{2}{c}{ Diferencia } \\
\cline { 2 - 6 } & 453 & 2511 & 1691 & -820 & $\begin{array}{c}\text { \% Respecto a } \\
2010\end{array}$ \\
\hline Extremo & 398 & 4378 & 2968 & -1410 & -32.66 \\
& 383 & 3029 & 2151 & -878 & -28.99 \\
\hline \multirow{2}{*}{ Muy Alto } & 580 & 2378 & 1724 & -654 & -27.50 \\
& 400 & 3968 & 2942 & -1026 & -25.86 \\
& 538 & 2854 & 2136 & -718 & -25.16 \\
& 595 & 1994 & 1528 & -466 & -23.37 \\
\hline & 468 & 4000 & 3108 & -892 & -22.30 \\
& 504 & 5283 & 4131 & -1152 & -21.81 \\
& 487 & 4384 & 3430 & -954 & -21.76 \\
& 491 & 4042 & 3208 & -834 & -20.63 \\
& 449 & 5345 & 4283 & -1062 & -19.87 \\
\hline & & & & &
\end{tabular}

\footnotetext{
${ }^{8}$ Se estimó la media, se sumó y restó la Desviación Estándar. Esto genera cuatro categorías replicables.
} 
Cuadro 3 (continuación)

\begin{tabular}{lccccc}
\hline $\begin{array}{c}\text { Rangos } \\
\text { de cambio de } \\
\text { población } \\
\text { (detrimento) }\end{array}$ & AGEB* & \multicolumn{2}{c}{ Población absoluta } & \multicolumn{2}{c}{ Diferencia } \\
\cline { 2 - 6 } & 434 & 4407 & 3569 & -838 & $\begin{array}{c}\text { A Respecto a } \\
2010\end{array}$ \\
\hline & 523 & 4585 & 3733 & -852 & -19.02 \\
& 110 & 3021 & 2480 & -541 & -18.58 \\
& 415 & 2828 & 2382 & -446 & -15.77 \\
Bajo & 379 & 6612 & 5844 & -768 & -11.62 \\
\hline
\end{tabular}

* Ver localización de cada AGEB en la figura 2 y mapa 1.

Fuente: elaboración propia a partir de los Censos de Población y Vivienda 2000 y 2010 (Inegi, 2011 a y 2011b).

La pérdida de población no se registró de manera homogénea en el CTN. La microzona que registra las mayores pérdidas de población (detrimento extremo) se localiza alrededor del zócalo, en una superficie de 141.33 hectáreas, equivalente a $17.2 \%$ de la superficie total del CTN (figura 2). Esta microzona cubre parte de las colonias Alameda, Santa Bárbara, Santa Clara, Centro y La Merced.

Parte de la explicación de la pérdida de población de rango Muy Alto de esta zona se debe al reemplazo de viviendas por comercios pequeños (que generan más renta del suelo que la vivienda, O’Sullivan, 2007) y, también, al surgimiento de sitios culturales (que aprovechan la accesibilidad del CTN), así como de oficinas públicas que resultan de la expansión de los gobiernos estatal, municipal y de los demás poderes autónomos (el Judicial y el Legislativo).

Esta microzona se encuentra enmarcada por las calles Sebastián Lerdo de Tejada y Paseo Matlazincas (que es una importante vialidad y límite clave del CTN, principalmente por su acentuada pendiente: Garrocho y Flores, 2009), por las avenidas Morelos (otra importante vialidad), De los Maestros e Isabel La Católica (otro límite clave del CTN: Garrocho y Flores, 2009).

La categoría de Muy Alto detrimento de población del CTN se localiza en dos zonas, que en conjunto suman 1588.99 hectáreas y represen$\tan 19.3 \%$ de la superficie del CTN. Entre sus límites encontramos parte de las colonias Ciprés, Militar, Universidad, Francisco Murguía, Doctores, Residencial Colón y Huitzila. Esta microzona limita al oeste con la microzona de detrimento Extremo de población (que gravita en torno al zócalo) (figura 2); esto sugiere que la microzona de detrimento Extremo de 
población se está expandiendo hacia el este, poniendo en riesgo inminente a la colonia Doctores y al barrio de San Sebastián.

La clase Alto detrimento de población se registra en ocho AGEB del CTN, que suman 380.75 hectáreas (46.3\% del CTN); estos AGEB forman un área continua que corre sobre la calle de Morelos (una de las más importantes del CTN). En esta clase encontramos parte de las siguientes colonias: Morelos primera sección, San Sebastián, San Bernardino, El Calvario, Américas, Villa Vista, Cinco de Mayo, La Merced y Francisco Murguía. Esta microzona funciona como buffer que contiene la expansión hacia el sur del área de Muy Alta pérdida poblacional.

Hay otra AGEB en la categoría Alto que corresponde al barrio de Santa Bárbara, cercano al zócalo. En esta zona, la pérdida de población responde también al reemplazo de vivienda por comercio al por menor (dirigido a población de ingresos medios y bajos) y a la construcción de inmuebles de gran tamaño, como el estacionamiento del Estadio Nemesio Diez ("La Bombonera"), plazas comerciales (e.g. Gran Plaza Toluca) y nuevas oficinas de la Universidad Autónoma del Estado de México, entre otros. ${ }^{9}$

Finalmente, la categoría Bajo detrimento poblacional se localiza en sólo dos AGEB, que suman 139.94 hectáreas (17\% del CTN). Un AGEB colinda con la microzona de Extrema pérdida de población y abarca parte de las colonias San Miguel Apinahuizco, La Retama, Unión y el Cóporo. La otra AGEB, aunque colinda con una zona de Muy Alta pérdida poblacional, parece protegida por la calle Isabel La Católica, límite clave del CTN en su extremo este, en ella encontramos a las colonias Ferrocarriles Nacionales, Fidel Velázquez, Reforma y Doctores (mapa 1).

Los resultados del análisis de la dinámica poblacional indican un claro despoblamiento del CTN. Esta pérdida poblacional representa un síntoma de decadencia, debido a que la población joven o económicamente activa se ve reducida (Flores et al., 2013) provocando un aumento de la población de adultos mayores. Tal incremento traerá consigo grandes retos para cubrir sus necesidades esenciales, por ejemplo: el aumento de la demanda de bienes y servicios de los adultos mayores, la dependencia económica, la falta de respeto hacia sus derechos humamos, entre otros, los cuales se deberán enfrentar en un futuro no muy lejano (Garrocho y Campos, 2016).

\footnotetext{
${ }^{9}$ Aunque el reemplazo de estos últimos no se llevó a cabo en el periodo de estudio, vale la pena mencionarlo debido a que en su momento propiciaron el despoblamiento en el CTN.
} 


\section{Mapa 1}

Intensidad de pérdida de población del CTN

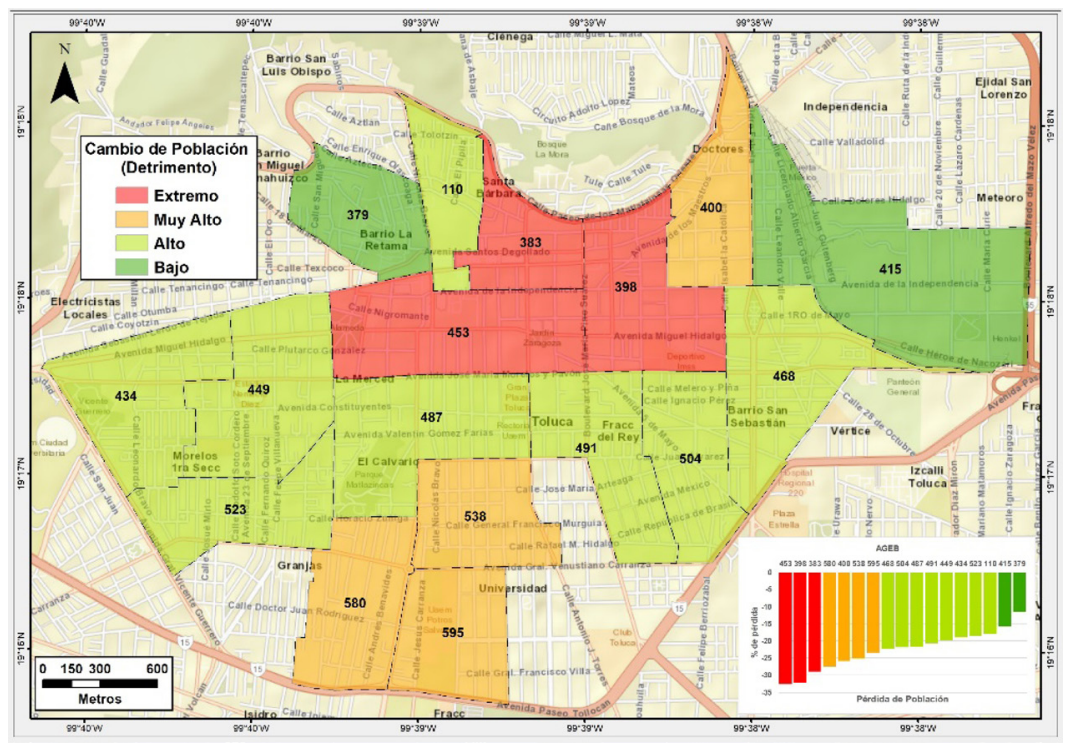

Fuente: elaboración propia a partir de los Censos de Población y Vivienda 2000 y 2010 (Inegi, 2011a y 2011b).

\section{Empleo}

\subsection{Evidencia 2: disponibilidad de empleo}

El CTN presentó un aumento en el número de empleos de $22.4 \%$ en el periodo de estudio; en 2000 existían 80,728 empleos y para 2010 había 98,847; en esta década se generaron 18,119 nuevos. Sin embargo, también se perdieron 1,879 en cuatro de las 17 AGEB (398, 580, 523 y 379). De acuerdo con Román y Cervantes (2013), la ciudad de Toluca ha presentado un aumento en el sector terciario de comercio y se ha convertido en una fuente generadora de empleo. Esta dinámica de terciarización del empleo también afecta al CTN (cuadro 4).

Los sectores de turismo, gubernamental e instancias públicas como la Universidad Autónoma del Estado de México y el Conservatorio de Música han sido los impulsores de manera directa o indirecta del comercio en el CTN. La categoría Aumento Muy Alto de empleo cubre una superficie de 152.2 hectáreas (18.5\% del CTN). En esta microzona encontramos parte de las colonias San Bernardino, Alameda, Morelos primera sección, Doctores, Centro, La Merced, Villa Vista y Huitzila.

Una de las razones por la que esta microzona presenta una alta disponibilidad de empleos se debe a que en ella se localizan "Los Portales" del 


\section{Cuadro 4}

Cambios en el empleo en el CTN por AGEB, 2000-2010

\begin{tabular}{|c|c|c|c|c|c|}
\hline \multirow{2}{*}{$\begin{array}{c}\text { Rangos } \\
\text { de cambio de empleo } \\
\text { (detrimentol } \\
\text { aumento) }\end{array}$} & \multirow[t]{2}{*}{$A G E B^{*}$} & \multicolumn{2}{|c|}{ Empleo } & \multicolumn{2}{|c|}{ Diferencia } \\
\hline & & 2000 & 2010 & Absoluta & $\begin{array}{c}\text { \% Respecto a } \\
2010\end{array}$ \\
\hline \multirow{3}{*}{ Extremo (detrimento) } & 580 & 2376 & 1808 & -568 & -23.9 \\
\hline & 398 & 5947 & 4861 & -1086 & -18.3 \\
\hline & 379 & 754 & 657 & -97 & -12.9 \\
\hline \multirow{4}{*}{$\begin{array}{l}\text { Detrimento o Aumento } \\
\text { Bajo }\end{array}$} & 523 & 1894 & 1766 & -128 & -6.8 \\
\hline & 468 & 6130 & 6302 & 172 & 2.8 \\
\hline & 415 & 8268 & 8765 & 497 & 6.0 \\
\hline & 487 & 7639 & 8752 & 1113 & 14.6 \\
\hline \multirow{7}{*}{ Alto (aumento) } & 383 & 6679 & 7982 & 1303 & 19.5 \\
\hline & 504 & 2886 & 3607 & 721 & 25.0 \\
\hline & 538 & 5454 & 6848 & 1394 & 25.6 \\
\hline & 491 & 4332 & 5443 & 1111 & 25.6 \\
\hline & 595 & 2120 & 2693 & 573 & 27.0 \\
\hline & 449 & 5042 & 6857 & 1815 & 36.0 \\
\hline & 110 & 2449 & 3401 & 952 & 38.9 \\
\hline \multirow{3}{*}{ Muy Alto (aumento) } & 400 & 3470 & 4996 & 1526 & 44.0 \\
\hline & 434 & 2515 & 3649 & 1134 & 45.1 \\
\hline & 453 & 12,773 & 20,460 & 7687 & 60.2 \\
\hline
\end{tabular}

* Ver la localización de cada AGEB en la figura 2 y mapa 2.

Fuente: elaboración propia a partir del Directorio Estadístico Nacional de Unidades Económicas (DENUE) (Inegi, 2018).

centro histórico, que se han especializado en comercio al por menor enfocado al sector turístico: artesanías, restaurantes, museos, zapaterías, entre otros. Esta categoría coincide con las clases más altas de pérdida poblacional (detrimento Extremo y Muy Alto).

La terciarización del empleo en el CTN se refleja en la clase de Aumento Alto de empleo. Esta clase cubre una superficie de 274.3 hectáreas que representan 33.4\% del CTN. La disponibilidad de empleo de esta microzona se debe a que en ella se encuentran oficinas de los poderes judicial y legislativo, además de tener en sus límites una de las principales atracciones turísticas que ofrece el CTN: el Cosmovitral. 
De igual forma se localizan diversos negocios e infraestructura relacionada con el equipo profesional Deportivo Toluca Futbol Club: desde el estadio, tienda oficial y museo, hasta pequeños comerciantes que se dedican a la venta de comida, así como diversos estacionamientos.

Esta microzona cubre parte de las colonias Santa Bárbara, Militar, San Sebastián, Morelos primera sección, Universidad, Américas, Universidad, Francisco Murguía, Villas Vista y Cinco de mayo. Tiene coincidencia con las clases Extremo, Muy alto y Alto detrimento de pérdida de población absoluta.

La clase de Detrimento o Aumento Bajo de empleo se distribuye en dos microzonas, localizadas al este y oeste del CTN, cubre una superficie de 263.2 hectáreas que corresponden a 32.1\% del CTN. Esta microzona se localiza en parte de las colonias Ferrocarriles Nacionales, Morelos primera sección, San Sebastián, El Calvario, Fidel Velázquez, La Merced, Reforma y Francisco Murguía. Coincide en parte con las categorías de Alto y Bajo detrimento de población absoluta; en ésta se localizan negocios importantes como Ford Sánchez Automotriz, RSO Toluca, Lumen, Triplay Market, entre otras; además, se localiza una subestación eléctrica de CFE, la residencia regional de la Junta de Caminos y la Comisión del Agua del Estado de México; incluso hay importantes lugares de esparcimiento como el Parque Matlazincas-El Calvario, Gran Plaza Toluca y sitios de servicios como escuelas, hospitales, consultorios médicos y odontológicos, farmacias y una amplia variedad de comercios al por menor como tiendas, zapaterías, florerías, mueblerías, entre otros.

En un poco más de un octavo de la superficie del CTN se perdieron empleos. Esto se refleja en la categoría de Extremo Detrimento de empleo, que cubre una extensión de 131.3 hectáreas: 16.0\% del CTN. La condición que le da a esta microzona el Extremo Detrimento de empleo es que esta área es prácticamente de uso habitacional, donde sólo se encuentran pequeñas tiendas y establecimientos de autoservicio. Esta categoría coincide con las clases más altas de pérdida poblacional absoluta. Dentro de los límites de esta microzona encontramos parte de la superficie de las colonias Ciprés, Santa Clara, Residencial Colón y San Miguel Apinahuizco.

En un principio se puede inducir que la terciarización del empleo que presenta el CTN supondría un aumento en la disponibilidad de empleo, pero este fenómeno actúa de manera inversa en el CTN (Garrocho y Campos, 2007; 2015) debido a que se crean pequeños negocios que ofrecen pocos empleos, en comparación con las grandes industrias que requieren u ofertan un gran número de éstos (mapa 2). 


\section{Mapa 2}

\section{Disponibilidad de empleo en el CTN}

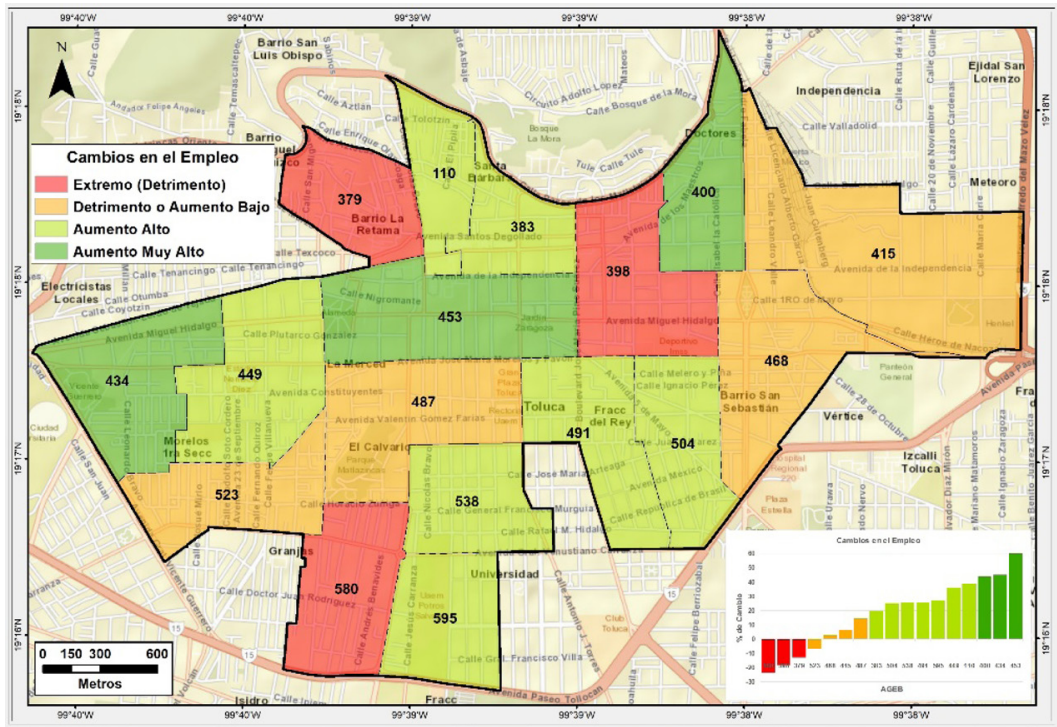

Fuente: elaboración propia a partir del Directorio Estadístico Nacional de Unidades Económicas (DENUE) (Inegi, 2018).

\section{Pobreza}

\subsection{Evidencia 3: Índice de Marginación Urbana}

Para analizar los cambios en el índice de marginación en el CTN se utilizó el Índice de Marginación Urbana (IMU) ${ }^{10}$ calculado por la Conapo (2016) para los años 2000 y 2010. Debido a la naturaleza de los cálculos del IMU (componentes principales) fue necesario realizar un análisis de posiciones relativas, que consistió en jerarquizar las AGEB de acuerdo con su grado de marginación para ambos años de análisis y observar los cambios que registraron cada una de ellas, con el fin de hacer comparables los datos en el periodo de estudio.

Existen tres panoramas en el CTN, el primero muestra las AGEB (538, $468,449,400,453,504$ y 595) que tienen decremento en el IMU, el segundo incluye las que se mantienen sin cambio $(523,580,110,379 \mathrm{y}$ 383) y en el tercero están aquéllas AGEB (491, 398, 487, 434 y 415) que mostraron cierta mejoría en sus condiciones relativas de vida (cuadro 5).

${ }^{10}$ El IMU es una medida-resumen que permite diferenciar AGEB urbanas del país según el impacto global de las carencias que padece la población como resultado de la falta de acceso a la educación, a los servicios de salud, la residencia en viviendas inadecuadas y la carencia de bienes (Conapo, 2012). 


\section{Cuadro 5}

Cambios del índice de marginación urbana del CTN

\begin{tabular}{|c|c|c|c|c|c|}
\hline \multirow[t]{2}{*}{$\begin{array}{c}\text { Rangos } \\
\text { de cambio del IMU }\end{array}$} & \multirow[t]{2}{*}{$A G E B^{*}$} & \multicolumn{2}{|c|}{$\begin{array}{l}\text { IMU (Posiciones } \\
\text { relativas) }\end{array}$} & \multicolumn{2}{|c|}{ Diferencia } \\
\hline & & 2000 & 2010 & Absoluta & $\begin{array}{c}\% \text { Respecto } \\
\text { a } 2010\end{array}$ \\
\hline \multirow{7}{*}{ Negativos } & 538 & 11 & 5 & -6 & -54.5 \\
\hline & 468 & 7 & 4 & -3 & -42.9 \\
\hline & 449 & 5 & 3 & -2 & -40.0 \\
\hline & 400 & 13 & 10 & -3 & -23.1 \\
\hline & 453 & 9 & 7 & -2 & -22.2 \\
\hline & 504 & 12 & 11 & -1 & -8.3 \\
\hline & 595 & 14 & 13 & -1 & -7.1 \\
\hline \multirow{5}{*}{ Sin Cambio } & 523 & 1 & 1 & 0 & 0.0 \\
\hline & 580 & 2 & 2 & 0 & 0.0 \\
\hline & 110 & 15 & 15 & 0 & 0.0 \\
\hline & 379 & 16 & 16 & 0 & 0.0 \\
\hline & 383 & 17 & 17 & 0 & 0.0 \\
\hline \multirow{3}{*}{ Mejora } & 491 & 6 & 8 & 2 & 33.3 \\
\hline & 398 & 10 & 14 & 4 & 40.0 \\
\hline & 487 & 8 & 12 & 4 & 50.0 \\
\hline \multirow{2}{*}{ Mejora Alta } & 434 & 3 & 6 & 3 & 100.0 \\
\hline & 415 & 4 & 9 & 5 & 125.0 \\
\hline
\end{tabular}

* Ver la localización de cada AGEB en la figura 2 y mapa 3.

Fuente: elaboración propia a partir del IMU de 2000 y 2010 (Conapo, 2016).

El deterioro del IMU se presentó en una superficie de 331.7 hectáreas que cubren $40.4 \%$ del CTN. Se distribuye en tres microzonas que abarcan parte de las colonias San Sebastián, Alameda, Militar, Morelos primera sección, Universidad, Américas, San Bernardino, Francisco Murguía, Doctores, Villa Vista, Centro, La Merced y Huitzila. Esta clase tiene coincidencia con las categorías más altas de pérdida de población absoluta y en contraparte coincide con Aumento Muy Alto, Alto y Bajo de disponibilidad de empleo. Lo cual significa que por una parte pierde población y por la otra aumenta la disponibilidad de empleo. 
Cinco AGEB mantuvieron sus condiciones relativas de vida de 2000 al 2010 (clase Sin Cambio). En su conjunto tienen una superficie de 176.9 hectáreas (21.6\% del CTN), localizándose en dos microzonas, que abarcan parte de las colonias Morelos primera sección, Santa Bárbara, Ciprés, Residencial Colón y San Miguel Apinahuizco. A pesar de que tienen coincidencia con las clases más altas de pérdida de población y de disponibilidad de empleo, estas AGEB mantuvieron sin cambio sus condiciones relativas de vida en el periodo analizado. La coincidencia que tiene con las clases de Aumento Alto y Bajo de disponibilidad de empleo ha contenido la pérdida de condiciones relativas de vida.

La clase de Mejora del IMU cubre una superficie de 98.4 hectáreas (11.98\% del CTN) y está conformada por dos microzonas que se expanden en las colonias San Bernardino, Morelos primera sección, Américas, Cinco de Mayo y Villa Vista. El Aumento Muy Alto y Alto de disponibilidad de empleos ha generado en esta clase que las condiciones relativas mejoren, a pesar de coincidir con la clase Alto detrimento de población absoluta.

La categoría de Mejora Alta está presente en tres microzonas que cubren una superficie de 214.1 hectáreas (26.1\% del CTN); dicha categoría está ligada con las clases de Extremo, Muy Alto y Bajo detrimento de población absoluta y a su vez presenta coincidencia con las clases de Aumento Alto y bajo de disponibilidad de empleos. Asimismo, se expande en parte de la superficie de las colonias Ferrocarriles Nacionales, El Calvario, Fidel Velázquez, Santa Clara, La Merced, Reforma y Francisco Murguía.

En el CTN se presentó mejoría en las condiciones relativas de vida. Si consideramos a las categorías Sin cambio, Mejora y Mejora Alta de esta variable, tenemos que casi $60 \%$ del territorio del CTN mejoró sus condiciones relativas de vida del 2000 al 2010, el aumento de empleo contribuye a la mejora de las condiciones relativas de vida de la población (mapa 3). 


\section{Mapa 3}

\section{Dinámica del índice de marginación urbana en el CTN}

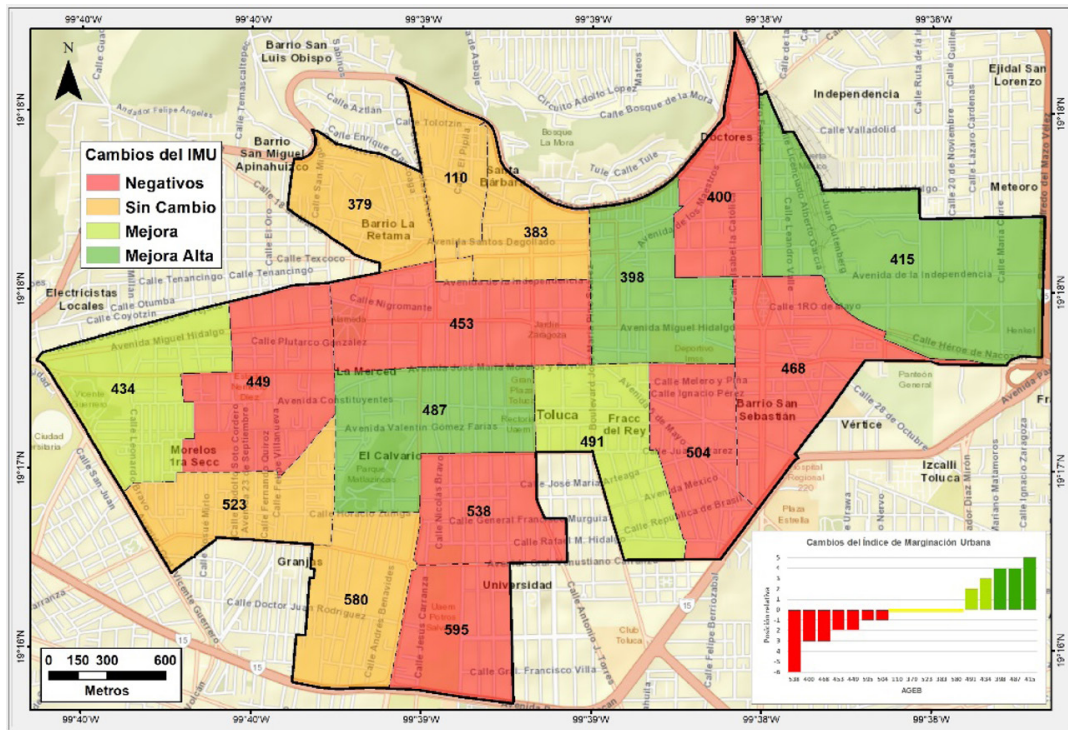

Fuente: elaboración propia a partir del IMU de 2000 y 2010 (Conapo, 2016).

\section{Indicador de decadencia para el CTN}

El análisis por separado de las evidencias muestra un panorama fragmentado de lo que sucede en el CTN. Debido a lo anterior fue necesario conjuntar los resultados de cada una de las evidencias con la finalidad de dar un diagnóstico más integral de la dinámica de decadencia del CTN. Es decir, consideramos cada una de las evidencias como sintomas que aportan datos, que permiten establecer los distintos niveles de decadencia que hay en el CTN. Para lograr lo anterior se realizó una sobreposición cartográfica de dichas evidencias (población, empleo y pobreza) generando una matriz de coincidencia ${ }^{11}$ con la que se definieron las clases de decadencia (cuadro 6).

En el CTN hay condiciones socioeconómicas que favorecen el proceso de decadencia. La clase de Decadencia Alta presenta los síntomas más desfavorables de decadencia, cubre una superficie de 158.1 hectáreas (19.3\% del CTN), se localiza al centro-norte del CTN y cubre parte de la superficie de las colonias Alameda, Santa Bárbara, Santa Clara, Centro y La Merced. En esta categoría las evidencias que más aportaron al proceso

${ }^{11}$ De acuerdo con Morales (2014) y Ramírez Sánchez et al. (2019), la relación espacial de Coincidencia es una de las relaciones más comunes, y se basa en el hecho de que dos o más eventos pueden compartir el mismo espacio en $n$ dimensiones. 


\begin{tabular}{|c|c|c|}
\hline \multicolumn{3}{|c|}{$\begin{array}{c}\text { Cuadro } 6 \\
\text { Definición de los grados de decadencia urbana del CTN }\end{array}$} \\
\hline$A G E B$ & Grado de decadencia & Definición \\
\hline $\begin{array}{l}453 \\
398 \\
383\end{array}$ & Decadencia Alta & $\begin{array}{l}\text { AGEB con valores extremos de pérdida de pobla- } \\
\text { ción absoluta, disminución considerable de opor- } \\
\text { tunidades de empleo y aumento en el nivel de } \\
\text { marginación. }\end{array}$ \\
\hline 580 & \multirow{5}{*}{$\begin{array}{l}\text { Decadencia } \\
\text { Moderada }\end{array}$} & \multirow{5}{*}{$\begin{array}{l}\text { AGEB con alta pérdida de población absoluta, } \\
\text { incremento leve de las oportunidades de empleo y } \\
\text { aumento en el nivel de marginación. }\end{array}$} \\
\hline 400 & & \\
\hline $\begin{array}{l}538 \\
595\end{array}$ & & \\
\hline 468 & & \\
\hline 504 & & \\
\hline 487 & \multirow{3}{*}{ Decadencia Baja } & \multirow{3}{*}{$\begin{array}{l}\text { AGEB con pérdida poblacional absoluta, aumento } \\
\text { leve de las oportunidades de empleo y disminución } \\
\text { del indicador de marginación. }\end{array}$} \\
\hline $\begin{array}{l}491 \\
449\end{array}$ & & \\
\hline 434 & & \\
\hline 523 & En Recuperación & $\begin{array}{l}\text { AGEB con baja pérdida poblacional absoluta, } \\
\text { aumento significativo en las oportunidades de } \\
\text { empleo y mejora significativa en el indicador de } \\
\text { marginación. }\end{array}$ \\
\hline
\end{tabular}

* Ver la localización de cada AGEB en la figura 2 y mapa 4.

Fuente: elaboración propia a partir de las evidencias de decadencia.

de decadencia fueron la "pérdida extrema" de población absoluta y el cambio negativo del IMU, aun cuando se registró aumento en el empleo (figura 3).

La categoría de Decadencia Moderada posee una superficie de 240.2 hectáreas (29.6\% del CTN), está conformada por dos microzonas localizadas al este y sur del CTN, afecta colonias como San Sebastián, Ciprés, Militar, Universidad, Américas, Francisco Murguía, Doctores, Residencial Colón y Huitzila. Las categorías que más aportaron a esta clase fueron: Extremo, Muy Alto y Alto detrimento de población absoluta y valores negativos del IMU, en tanto que el empleo presentó un Aumento Muy Alto y Alto (figura 4).

La clase de Decadencia Baja tiene una superficie de 214.5 hectáreas (26.1\% del CTN), se localiza en el centro-oeste del CTN, entre las colonias que encontramos en esta clase están San Bernardino, El Calvario, More- 


\section{Figura 3}

\section{Indicador de decadencia: Decadencia Alta}

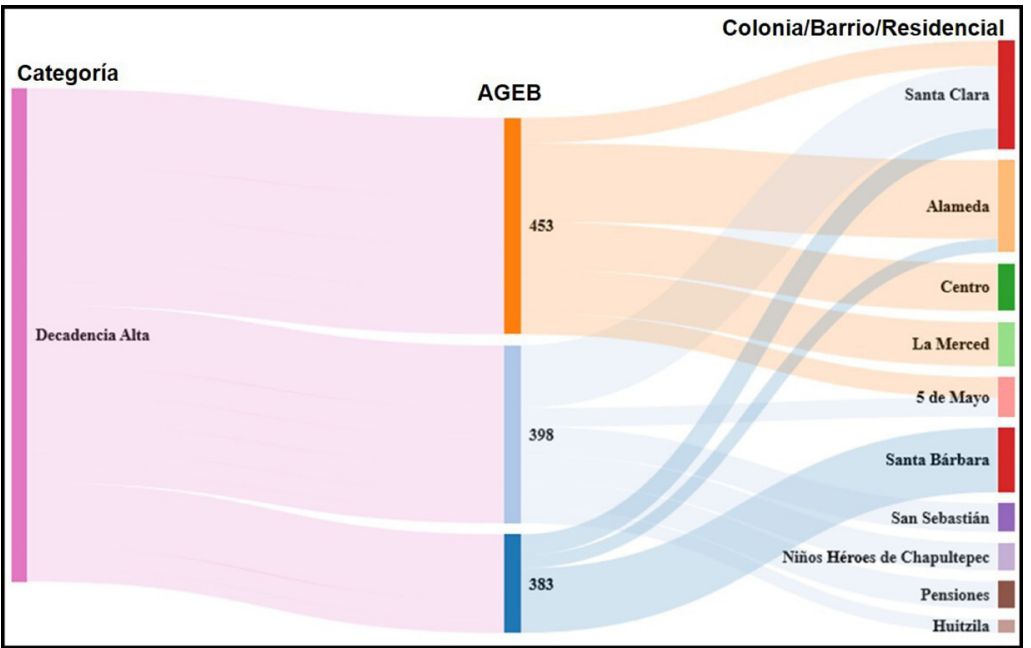

Fuente: elaboración propia a partir de las evidencias de decadencia.

Figura 4

Indicador de decadencia: Decadencia Moderada

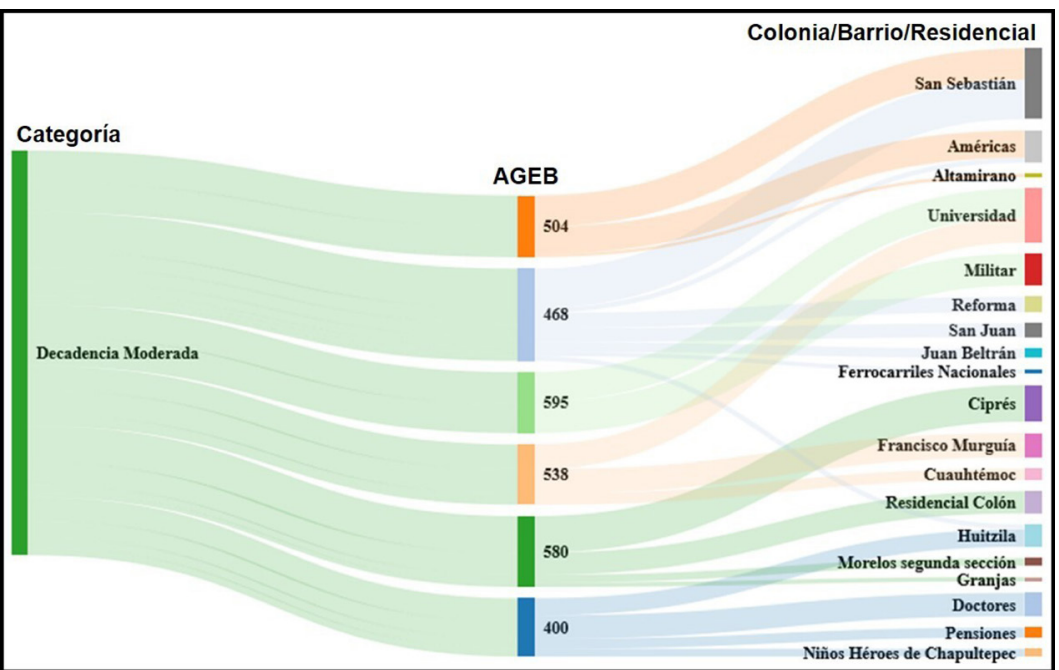

Fuente: elaboración propia a partir de las evidencias de decadencia. 
los primera sección, Américas, Villa Vista, Cinco de Mayo, La Merced y Francisco Murguía. En esta categoría se tiene que la evidencia de mayor aporte negativo fue la población absoluta, en contraparte tenemos a las evidencias de empleo e IMU como las que favorecieron de manera positiva a esta categoría (figura 5).

\section{Figura 5}

Indicador de decadencia: Decadencia Baja

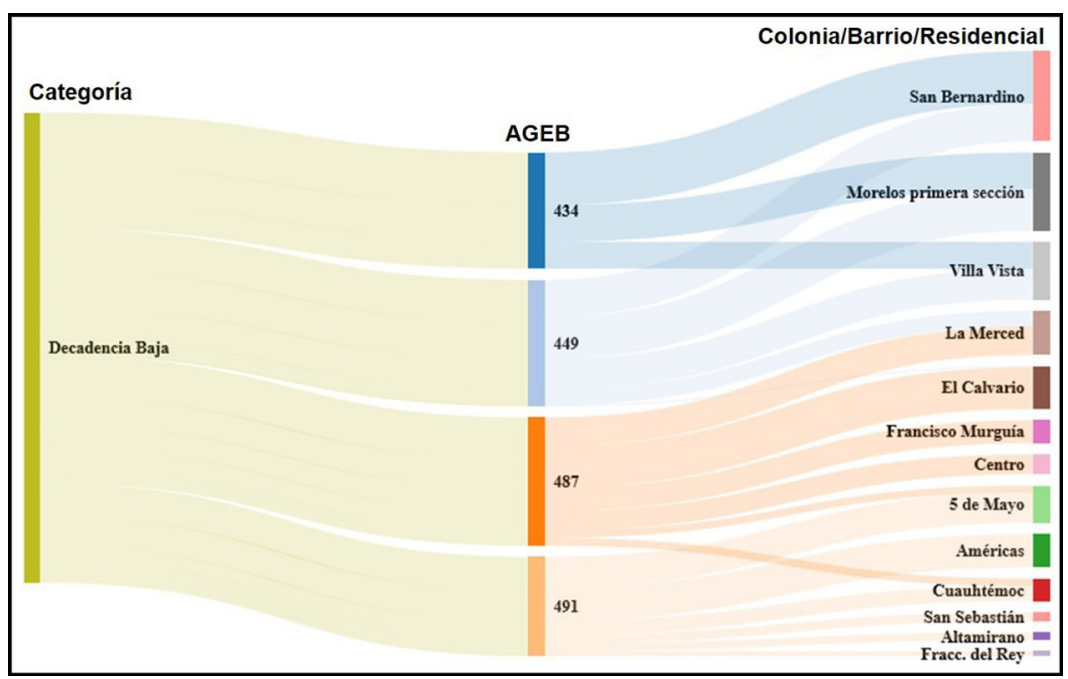

Fuente: elaboración propia a partir de las evidencias de decadencia.

La categoría de En Recuperación tiene una superficie de 208.3 hectáreas que corresponden a $25.37 \%$ del CTN. Está presente en tres microzonas, la primera de ellas (62.2 hectáreas que corresponden a $7.6 \%$ del CTN) se encuentra al norte del CTN, en ésta se puede apreciar que las evidencias que más aportaron de manera positiva fueron empleo (Aumento Alto) e IMU (Sin Cambio y Mejora Alta), en contraparte tenemos a las clases de Bajo detrimento de población absoluta (figura 6).

El CTN parece estar en proceso de decadencia diferenciada; en las microzonas de decadencia Alta, Moderada y Baja se deben centrar las estrategias y políticas de recuperación por parte de instancias gubernamentales, asociaciones empresariales y dueños de los inmuebles para evitar que su nivel avance y sea posible revertirlo; deben ser prioridad porque se encuentran en un punto clave: la acción o inacción puede determinar la mejora de la situación o el aumento de la decadencia (mapa 4).

Para el caso específico del CTN, la variable que más aporte tuvo en la decadencia fue la Población, ya que en su conjunto presentó pérdidas 


\section{Figura 6}

\section{Indicador de decadencia: En Recuperación}

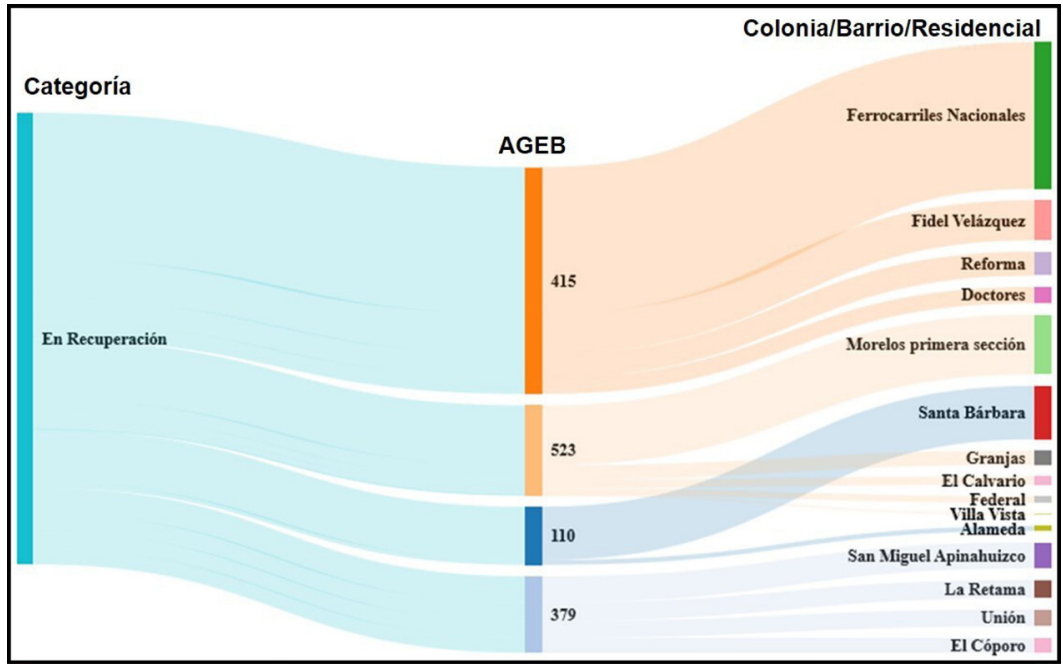

Fuente: elaboración propia a partir de las evidencias de decadencia.

\section{Mapa 4}

\section{Tipos de decadencia en el CTN}

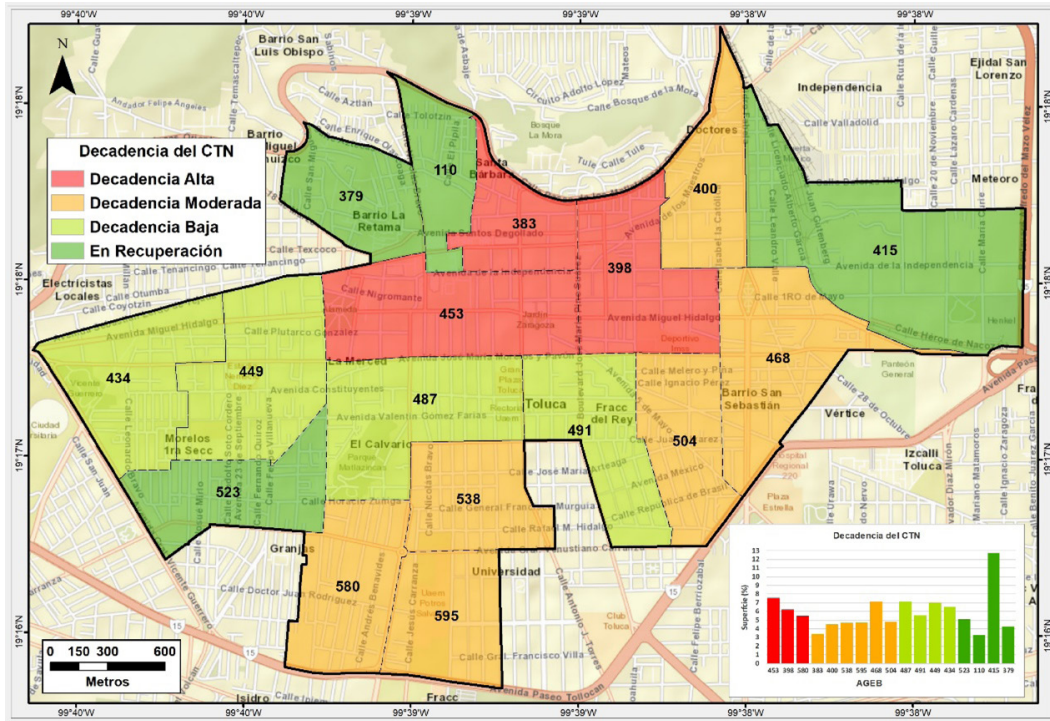

Fuente: elaboración propia a partir de las evidencias de decadencia. 
considerables en todas las AGEB. En segunda instancia se puede considerar al IMU, ya que por sí solo es un indicador resumen de las condiciones de vida que presenta la población en un área dada.

Finalmente, el empleo es la variable que nos indica que el CTN aún es atractivo, que presenta un proceso de desplazamiento de población residente por actividades económicas del sector terciario, principalmente. Sin embargo, se trata de empleo en negocios pequeños y no en firmas de calidad que se han desplazado a los centros comerciales planificados, localizados fuera del CTN (e.g. Metepec) (Garrocho y Campos, 2007; 2015).

\section{Conclusiones}

El acelerado proceso de despoblamiento ha sido generalizado en todo el CTN, se ha perdido uno de cada cinco habitantes en el periodo analizado. La dinámica poblacional presenta tres aristas: la primera es en relación con el abandono de la población que tiene el potencial de ser económicamente activa ( 15 a 64 años), la segunda está asociada al envejecimiento poblacional (población de más de 65 años) y la tercera va en relación con el reemplazo de la vivienda por negocios al por menor y el establecimiento de grandes inmuebles (estadio de futbol "La Bombonera", estacionamientos, oficinas gubernamentales, universitarias, entre otras).

Para el caso específico del CTN, la disponibilidad de empleo es un espejismo de mejora, si bien ha aumentado el empleo, esta oferta laboral se ve opacada por lo que mencionan Garrocho y Campos (2007; 2015): el CTN tiene una terciarización del empleo, lo cual ha derivado en la creación de pequeños negocios que ofrecen pocos empleos, comparados con la oferta de los que podrían generar las grandes firmas de comercios. El hecho de que el alquiler del suelo sea más rentable que la vivienda (O'Sullivan, 2007) favorece al reemplazo paulatino pero consistente de vivienda (pérdida de población) por pequeños negocios (empleos de baja calidad).

Por su parte, el IMU nos muestra que en el CTN han mejorado las condiciones relativas de vida en casi $40 \%$ de su superficie; se mantiene una relación muy estrecha entre la mejora de las condiciones relativas de vida y el aumento en la disponibilidad de empleo y viceversa.

En términos generales se puede mencionar que el CTN se encuentra en una etapa incipiente de decadencia. Las evidencias analizadas muestran relación entre sí, mas no dependencia, esta relación va en el sentido del aporte que tiene cada una de las evidencias en la decadencia del CTN, debido a que hay variables que apuntan hacia su mejoría (oportunidades 
de empleo), otras apuntan hacia el deterioro (pérdida de población) y algunas tienden a mantenerse relativamente estables (IMU).

A pesar de lo anterior, el CTN aún es un área viva y mantiene su condición: A. Espacial (centralidad), es un lugar de encuentro de población que supera su espacio (transterritorialidad) y B. Temporal (historia), donde convergen diferentes sociedades procedentes de distintos tiempos y momentos históricos (transtemporalidad) (Carrión, 2005).

Este trabajo está orientado a apoyar la formulación de políticas públicas, por eso la metodología aplicada es sencilla (aportación), pero muy útil, con la idea de que los gobiernos municipales puedan replicarla de una manera rápida y eficaz. De igual manera se reconoce que las principales limitaciones están en función de la disponibilidad de datos, debido a que en muchas ocasiones no se encuentran disponibles a la escala en que se desea realizar el análisis.

De acuerdo con los resultados obtenidos se recomienda que en las microzonas con algún grado de decadencia (Alta, Moderada y Baja) se apliquen de manera prioritaria todas aquellas acciones que ayuden a prevenir el avance y que puedan, incluso, revertir el fenómeno de decadencia que enfrenta el CTN.

Si bien este trabajo se enfocó en el periodo 2000-2010, será conveniente realizar el mismo análisis entre los años 2010 y 2020 con la finalidad de realizar una comparación entre periodos y conocer si el proceso de decadencia avanzó, se mantuvo o se revirtió en el CTN.

\section{Fuentes consultadas}

Arteaga, Isabel (2005), "De periferia a ciudad consolidada. Estrategias para la transformación de zonas urbanas marginales", Revista Bitácora Urbano Territorial, 9 (1), Bogotá, Universidad Nacional de Colombia, pp. 98-111 <https://www.redalyc.org/articulo. oa?id=748/74800909>, 19 de febrero de 2020 .

Bingham, Richard (2018), The economies of central city neighborhoods, Nueva York, Routledge.

Burgess, Ernest (1925), “The growth of the city”, en Robert Park, Ernest Burgess y Robert McKenzie (eds.), The City, Chicago, University of Chicago Press, pp. 47-62.

Campos Cortés, Georgina Isabel (2011), "El origen de la plaza pública en México: usos y funciones sociales”, Argumentos, 24 (66), Ciu- 
dad de México, Universidad Autónoma Metropolitana unidad Xochimilco, pp. 83-119.

Carrión, Fernando (2010), El laberinto de las centralidades históricas en América Latina. El centro histórico como objeto de deseo, Quito, Ministerio de Cultura.

Carrión, Fernando (2005), "El centro histórico como proyecto y objeto de deseo", Eure, 31 (93), Santiago de Chile, Pontificia Universidad Católica de Chile/Instituto de Estudios Urbanos y Territoriales, pp. 89-100.

Conapo (Consejo Nacional de Población) (2016), "Datos abiertos del índice de marginación, 2000 y 2010", Ciudad de México, Conapo, <http://www.conapo.gob.mx/es/CONAPO/Datos_ Abiertos_del_Indice_de_Marginacion>, 18 de diciembre de 2019.

Conapo (Consejo Nacional de Población) (2012), "Proyecciones de la población de México 2010-2050”, Ciudad de México, Conapo, $<$ http://www.conapo.gob.mx/work/models/CONAPO/Resource/1529/2/images/DocumentoMetodologicoProyecciones2010_2050.pdf>, 18 de diciembre de 2019.

Conapo (Consejo Nacional de Población) (2012), "Proyecciones de la población de México 2010-2050”, Ciudad de México, Conapo, $<$ http://www.conapo.gob.mx/work/models/CONAPO/Resource/1529/2/images/DocumentoMetodologicoProyecciones2010_2050.pdf>, 18 de diciembre de 2019.

Coulomb, René (2018), "Sustentabilidad de la centralidad urbana e histórica. Una reflexión desde el centro histórico de la ciudad de México", Quivera. Revista de Estudios Territoriales, 10 (2), Toluca, Universidad Autónoma del Estado de México, pp. 29-49.

Coulomb, René (2012), "El centro de la ciudad de México frente al desafío de un desarrollo urbano más sustentable (elementos para el proyecto de investigación 'Hábitat y Centralidad')", en René Coulomb, Teresa Esquivel y Gabriela Ponce (eds.), Hábitat y centralidad en México: un desafío sustentable, Ciudad de México, Cámara de Diputados/Centro de Estudios Sociales y de Opinión Pública, pp. 17-57. 
Díaz, Fernando (2011), "Las agendas urbanas en España: una perspectiva socioeconómica”, Eixo Atlântico. Revista da Eurorregiäo Galicia Norte de Portugal, núm. 18, Pontevedra, Fundación Dialnet, pp. 43-54.

Díaz Núñez, Verónica y Escamilla Galindo, Livier (2018), "Las nuevas centralidades como factores de desarrollo intraurbano: caso de estudio, Puerto Vallarta, Jalisco", en Daniel Romero, María Teresa Pérez y Jorge Octavio Ocaranza (coords.), Ciudad siglo 21 un debate necesario. Tomo II, Guadalajara, Universidad de Guadalajara, pp. 180-198.

Fisher, Joseph y Wingo, Lowdon, (2017), “Directions for metropolitan policy", en Mark Perlman, Charles Leven y Benjamin Chinitz (eds.), Spatial, regional and population economics, Nueva York, Routledge, pp. 169-191.

Flores, Zochilt; Garrocho, Carlos y Álvarez Lobato, Antonio (2013), “El comportamiento intrametropolitano del empleo terciario en el Centro Tradicional de Toluca, 1999-2004. ¿Auge, decadencia o equilibrio?", en Susana Medina (coord.), Contribución al estudio de las ciudades el Estado de México y el suelo urbano, Zinacantepec, El Colegio Mexiquense, A. C., pp. 123-196.

Fuentes, César y Hernández, Vladimir (2015), "La evolución espacial de los subcentros de empleo en Ciudad Juárez, Chihuahua (19942004): un análisis con indicadores de autocorrelación espacial global y local", Estudios demográficos y urbanos, 30 (2), Ciudad de México, El Colegio de México, pp. 433-467.

Garrocho, Carlos (1994), “¿Decadencia del centro de la Ciudad de México?: de los problemas en la ciudad central a los problemas de la ciudad central", Vivienda, 5 (1), Ciudad de México, Infonavit, pp. 7-30.

Garrocho, Carlos y Campos, Juan (2016), Segregación socioespacial de la población mayor en la Ciudad de México: la dimensión desconocida del envejecimiento, Zinacantepec, El Colegio Mexiquense, A. C.

Garrocho, Carlos y Campos, Juan (2015), "Segregación de la población mayor en la Ciudad de México" en Consejo Nacional de Población (ed.), La situación demográfica de México 2015, Ciudad de México, Conapo, pp. 167-198. 
Garrocho, Carlos y Campos, Juan (2009), "Estructura espacial del empleo terciario en el Área Metropolitana de Toluca, 1993-2003”, en Gustavo Garza y Luis Sobrino (coords.), Evolución del sector servicios en ciudades y regiones de México, Ciudad de México, El Colegio de México, pp. 827-875.

Garrocho, Carlos y Campos, Juan (2007), “Dinámica de la estructura policéntrica del empleo terciario en el área metropolitana de Toluca, 1994-2004”, Papeles de población, 13 (52), Toluca, Universidad Autónoma del Estado de México/Centro de Investigación y Estudios Avanzados de la Población, pp. 109-135.

Garrocho, Carlos y Flores, Zochilt (2009), “Delimitación del centro tradicional de comercio y servicios del área Metropolitana de Toluca", Papeles de Población, 15 (61), Toluca, Universidad Autónoma del Estado de México/Centro de Investigación y Estudios Avanzados de la Población, pp. 233-274.

Ghose, Rina y Huxhold, William (2017), “The role of multi-scalar GISbased indicators studies in formulating neighborhood planning policy", en Rhonda Phillips (ed.), Community indicators measuring systems, Nueva York, Routledge, pp. 157-177.

González Hernández, Guadalupe Margarita (2018), "Entre la regeneración y la suburbanización: Centro Histórico de Zacatecas, México", Limaq, núm. 4, Lima, Universidad de Lima, pp. 37-58.

Gregory, Derek; Johnston, Ron; Pratt, Geraldine; Watts, Michael y Whatmore, Sarah (2009), The dictionary of human geography, Chichester, Wiley-Blackwell.

Haase, Annegret; Kabisch, Sigrun y Steinführer, Annett (2006), "Aufschwung der inneren Stadt in Europa?: Reurbanisierung unter den Bedingungen des demographischen Wandels im internationalen Vergleich”, Europa Regional, 14 (4), Schongauerstraße, Leibnizinstitut für länderkunde-Social Science Open Access Repository, pp. $167-180<$ https://bit.ly/34PZWMd>, 25 de febrero de 2020

Haase, Annegret; Steinführer, Annett y Kabisch, Sigrun (2003), “Understanding, hypotheses and key indicators of reurbanisation with reference to demographic change", Bruselas, Framework Program of the EU. 
Hall, Peter (2014), Good cities, better lives: How Europe discovered the lost art of urbanism, Londres, Routledge.

Hiernaux, Daniel y González, Carmen Imelda, (2008), “¿Regulación o desregulación? De las políticas sobre los centros históricos", Centro-h, núm. 1, Quito, Organización Latinoamericana y del Caribe de Centros Históricos, pp. 40-50.

Inegi (Instituto Nacional de Estadística y Geografía) (2018), "Directorio Estadístico Nacional de Unidades Económicas, 2010 y 2015”, Ciudad de México, Inegi, <https://www.inegi.org.mx/app/mapa/ denue/>, 18 de diciembre de 2019.

Inegi (Instituto Nacional de Estadística y Geografía) (2011a), "Censo de población y vivienda 2000", Ciudad de México, Inegi, <https:// www.inegi.org.mx/programas/ccpv/2000/>, 18 de diciembre de 2019.

Inegi (Instituto Nacional de Estadística y Geografía) (2011b), “Censo de población y vivienda 2010", Ciudad de México, Inegi, <https:// www.inegi.org.mx/programas/ccpv/2010/>, 18 de diciembre de 2019.

Jorgenson, Andrew; Rice, James y Clark, Brett (2010), "Cities, slums, and energy consumption in less developed countries, 1990 to 2005", Organization \& Environment, 23 (2), Thousand Oaks, Sage Journals, pp.189-204.

Lawless, Paul (1996), "The inner cities: towards a new agenda", Town Planning Review, 67 (1), Liverpool, Liverpool University press, pp. 21-43, doi:10.3828/tpr.67.1.98h00465j93w0386

Leduff, Charlie (2014), Detroit: an American autopsy, Nueva York, Penguin.

Matthews, Hugh (1991), British inner cities, Oxford, Oxford University Press.

Morales Manilla, Luis Roberto (2014), "The definition of a minimum set of spatial relations", tesis de doctorado en Geografía, Universidad Nacional Autónoma de México/Facultad de Filosofía y Letras, Ciudad de México.

O’Sullivan, Arthur (2007), Urban economics, Boston, McGraw-Hill/Irwin. 
Pauta, Fernando (2019), "La vivienda y la renovación urbana en los centros históricos. Un estudio de caso sobre Cuenca (Ecuador)", Estoa. Revista de la Facultad de Arquitectura y Urbanismo de la Universidad de Cuenca, 8 (15), Cuenca, Universidad de Cuenca, pp. 197-228.

Ramírez Sánchez, Luis Giovanni (2020), “Dinámica del empleo en el Centro Tradicional de Negocios de Toluca (México), 2010-2018: Cambio y Participación Espacial", Región y Sociedad, Hermosillo, El Colegio de Sonora (en prensa).

Ramírez Sánchez, Luis Giovanni; Morales Manilla, Luis; Vilchis Mata, Iván; Trujillo Herrada, Armando y Castelo Agüero, Danays (2019), "Evaluación territorial para el cultivo del aguacate (Persea americana Mill. cv. Hass) en la región del pico de Tancítaro, Michoacán, México", Agrociencia, 53 (4), Texcoco, Secretaría de Agricultura y Desarrollo Rural/Colegio de Posgraduados, pp. 487-503.

Robson, Brian (1988), Those inner cities, Oxford, Clarendon Press.

Román, Yuliana y Cervantes, David (2013), "El empleo precario de jóvenes asalariados en México: el caso de Toluca, Tijuana y Mérida (2005-2010)", Revista Facultad de Ciencias Económicas: Investigación y Reflexión, 21 (1), Bogotá, Universidad Militar Nueva Granada, pp. 43-74.

Salazar, Clara y Sobrino, Jaime (2010), "La ciudad central de la Ciudad de México: ¿espacio de oportunidad laboral para la metrópoli?”, Estudios demográficos y urbanos, 25 (3), Ciudad de México, El Colegio de México, pp. 589-623.

Salinas Arreourtua, Luis Alberto (2013), "Reciclamiento urbano: como una premisa en la planeación del desarrollo urbano de la ciudad de México", GeoGraphos: Revista Digital para Estudiantes de Geografia y Ciencias Sociales, 4 (55), Alicante, Grupo Interdisciplinario de Estudios Críticos y de América Latina de la Universidad de Alicante, pp. 553-569.

Shen, Jianfa y Kee, Gordon (2017), Development and planning in seven major coastal cities in southern and eastern China, Berlín, Springer. 
Simmons, Jim; Garrocho, Carlos; Kamikihara, Shizue y Campos, Juan (2018), "The evolving retail structure of Mexico City", Papers in Applied Geography, 4 (3), Londres, Taylor and Francis, pp. 305-325.

Simmons, Jim; Garrocho, Carlos y Kamikihara, Shizue (2016), "La estructura del comercio al por menor en la Ciudad de México", en Guillermo Aguilar, La Ciudad de México en el Siglo XXI, Ciudad de México, Universidad Nacional Autónoma de México/Porrúa, pp. 415-424.

Sobrino, Jaime (2007), "Patrones de dispersión intrametropolitana en México", Estudios demográficos y urbanos, 22 (3), Ciudad de México, El Colegio de México, pp. 583-617.

Stewart, Murray (1986), "Ten years of inner cities policy", The Town Planning Review, 58 (2), Liverpool, Liverpool University Press, pp.129-145, doi:10.3828/tpr.58.2.4t36w36168176353.

Suárez-Lastra, Manuel y Delgado-Campos, Javier (2010), "Patrones de movilidad residencial en la Ciudad de México como evidencia de co-localización de población y empleos", Eure, 36 (107), Santiago de Chile, Pontificia Universidad Católica de Chile/ Instituto de Estudios Urbanos y Territoriales, pp. 67-91.

Tommei, Constanza y Benedetti, Alejandro (2014), "De ciudad-huerta a pueblo boutique: turismo y transformaciones materiales en Purmamarca", Revista de Geografía Norte Grande, núm. 58, Santiago de Chile, Pontificia Universidad Católica de Chile/Instituto de Geografía, pp. 161-177.

Toribio, José (2004), "Problemas de definición de las áreas metropolitanas en España”, Boletín de la Asociación de Geógrafos Españoles, núm. 38, Sevilla, Asociación de Geógrafos Españoles, pp. 85-100.

Turok, Ivan; Seeliger, Leanne y Visagie, Justin (2019), "Restoring the core? Central city decline and transformation in the South", Progress in Planning, Elsevier, e100434.

Vecslir, Lorena (2019), "Tensiones y desfasajes entre modelos y planeamiento de la centralidad metropolitana de Buenos Aires (1970-2018)", Quid 16. Revista del Área de Estudios Urbanos, núm. 12, Buenos Aires, Instituto de Investigaciones Gino Germani, pp. 10-41. 
Wagner, Fritz; Joder, Timothy y Mumphrey, Anthony (2019), Managing capital resources for central city revitalization, Nueva York, Garland Publishing Inc.

Wilson, William; Quane, James y Rankin Bruce (1998), The new urban poverty: consequences of the economic and social decline of inner-city neighborhoods, Washington, The Milton S. Eisenhower Foundation.

Ziccardi, Alicia (2019), "Nueva arquitectura espacial, pobreza urbana y desigualdad territorial”, Polis, 15 (1), Ciudad de México, UAM, Unidad Iztapalapa, División de Ciencias Sociales y Humanidades, pp. 7-31.

Recibido: 4 de marzo de 2020. Reenviado: 17 de julio de 2020. Aceptado: 20 de agosto de 2020.

Luis Giovanni Ramírez Sánchez. Doctor en geografía por el Centro de Investigaciones en Geografía Ambiental UNAM, campus Morelia. Actualmente es catedrático Conacyt comisionado a El Colegio Mexiquense, A. C.; es profesor en el Centro de Investigaciones en Geografía Ambiental-Universidad Nacional Autónoma de México-Morelia, la Universidad de Guadalajara y la Universidad de Guanajuato. Es miembro del Sistema Nacional de Investigadores, nivel candidato. Su línea de investigación actual es Análisis espacio-temporal de espacios urbanos. Entre sus más recientes publicaciones se encuentran, como autor: "Evaluación territorial para el cultivo del aguacate (Persea americana Mill. cv. Hass) en la región del pico de Tancítaro, Michoacán, México", Texcoco, Agrociencia, 53 (4), Texcoco, Secretaría de Agricultura y Desarrollo Rural-Colegio de Posgraduados, pp. 487-503 (2019); "Estado de la heterogeneidad geológica en las áreas naturales protegidas en Michoacán”, en Margarita Anaya y Heriberto Cruz (coord.), Caracterización de paisajes en el territorio del Occidente de México, Guadalajara, Astra ediciones, S.A. de C.V. (próximamente); como coautor: "Inclusión de la variable espacial en la medición de las condiciones relativas de vida en ciudades latinoamericanas: conceptos, método y aplicación", Papeles de Población, Toluca, Universidad Autónoma del Estado de México (próximamente). 